\title{
Diagnóstico de la hemorragia subaracnoidea espontánea de escasa cuantía o de larga evolución: a propósito de un caso
}

\author{
E. ALONSO FORMENTO, F. RODERO ÁLVAREZ, C. M. ROS TRISTÁN', \\ M. J. CALPE GIL ${ }^{1}$, A. MARTÍNEZ OVIEDO \\ Servicios de Urgencias $y^{\prime}$ Medicina Interna. Hospital General Obispo Polanco. Teruel
}

\section{RESUMEN}

La hemorragia subaracnoidea implica la presencia en el espacio subaracnoideo de sangre proveniente de un proceso patológico. La prueba inicial de elección es una Tomografía Axial Computerizada craneal urgente, pero su sensibilidad disminuye con el tiempo. Se recomienda, por tanto, que a los pacientes con una cefalea brusca severa, pero con una Tomografía Axial Computerizada craneal normal, se les debería practicar una punción lumbar, después de las primeras 12 horas del comienzo de los síntomas, para descartar una hemorragia subaracnoidea.

Los métodos para diferenciar entre una punción lumbar traumática y una verdadera hemorragia subaracnoidea incluye el recuento de hematíes, "la prueba de los tres tubos", el dímero-D y la ferritina en líquido cefalorraquídeo.

Pero la mejor técnica es la xantocromía ó sobrenadante amarillonaranja en líquido cefalorraquídeo, valorado por espectrofotometría.

Presentamos el caso de una mujer joven con una hemorragia subaracnoidea diagnosticada mediante xantocromía tras 18 días del comienzo del sangrado.

PALABRAS CLAVE: Hemorragia subaracnoidea. Punción lumbar. Xantocromía. Espectrofotometría.
DIAGNOSIS OF THE SPONTANEOUS SUBARACHNOID HEMORRHAGE WITH SHORT BLEEDING OR LONG EVOLUTION: REPORT OF ONE CASE

\section{ABSTRACT}

Subarachnoid hemorrhage implies the presence of blood within the subarachnoid space from some pathologic process. The initial study of choice is an urgent Cranial Computed Tomography scan, but its sensitivity declines with time. So that it is recommended that patients with severe sudden headache but normal Cranial Computed Tomography scan, should have a lumbar puncture performed, more than 12 hours after the onset of symptoms, to rule out subarachnoid hemorrhage.

The methods for distinguishing among traumatic lumbar puncture and true Subarachnoid hemorrhage include the erythrocyte level, the "three tube test", D-dimer assay and ferritin in cerebrospinal fluid.

But the best technique is the xanthochromia o yellow-to-orange cerebrospinal fluid supernatant, measured spectrographically.

We report a case of a young woman with a subarachnoid hemorrhage diagnosed by xanthochromia after 18 days after the onset of bleeding.

KEY WORDS: Subarachnoid hemorrhage. Humbar puncture. Xanthochromia. Spectrophotometry.

Alonso Formento E, Rodero Álvarez F, Garzarán Teijeiro A, Calpe Gil MJ, Martínez Oviedo A. Diagnóstico de la hemorragia subaracnoidea espontánea de escasa cuantía o de larga evolución: a propósito de un caso. An Med Interna (Madrid) 2008; 25: 353-355.

\section{INTRODUCCIÓN}

La hemorragia subaracnoidea (HSA) se define como la presencia de sangre en el espacio subaracnoideo y en las cisternas de la base (1).

Se clasifican según su etiología en traumáticas o espontáneas, y estas últimas pueden deberse a la ruptura de aneurismas intracraneales o malformaciones arteriovenosas, problemas vasculares (vasculitis, disecciones arteriales, trombosis cortical...), tumores que sangran en el espacio subaracnoideo o no detectarse su causa (1).

El $80 \%$ de las HSA están originadas por la rotura de aneurismas intracranelaes. Existen factores de riesgo asociados a éstos como son el consumo de alcohol (más de 40 gramos), el tabaco, la hipertensión arterial, el embarazo, el parto, los anticonceptivos orales y las sustancias tóxicas como la cocaína (2). Puede haber una fuerte historia familiar, como ocurre en los casos de coartación de aorta, riñones poliquísticos, enfermedad del colágeno tipo III, neurofibromatosis I y Síndrome de Marfan.

$\mathrm{Su}$ incidencia es mayor en las mujeres, con una edad media de 50 años (3).

La HSA es una patología con una elevada morbimortalidad, ya que un alto porcentaje de pacientes (10-15\%) fallecen antes de llegar al Servicio de Urgencias del Hospital, otros (15\%) fallecen en las 4 siguientes semanas, y de los que

Trabajo aceptado: 24 de marzo de 2008 
sobreviven aproximadamente el 50\% tienen secuelas neurológicas (3).

Por este motivo es crucial llegar cuanto antes a un diagnóstico definitivo de esta entidad, para poder planificar las pruebas diagnósticas y el plan terapéutico necesario.

La HSA es una emergencia médica, siendo esencial su diagnóstico precoz e ingreso para tratamiento del paciente en un medio adecuado.

El primer paso para su diagnóstico será la sospecha clínica. El síntoma más frecuente es la cefalea, que suele ser de inicio brusco, intensa, continua, relacionada con el ejercicio o maniobras de Valsalva, y que puede ir seguido de otros síntomas como náuseas, vómitos, fotofobia, síntomas meníngeos, signos neurológicos focales, y pérdida de conciencia.

A veces estos pacientes refieren los días previos una cefalea "centinela" por un pequeño sangrado.

En la exploración física debemos buscar signos meníngeos y alteración del nivel de conciencia, aunque no siempre están presentes (4).

Es importante estimar el grado clínico inicial del paciente según la escala de Hunt Hess, para adecuar la actitud terapéutica y valorar el probable pronóstico final.

Una vez establecida la sospecha clínica de la HSA, la prueba diagnóstica inicial en el Servicio de Urgencias será la Tomografía Axial Computerizada (TAC), sin contraste, que puede demostrar la presencia de sangre en las cisternas basales o el espacio subaracnoideo, y además puede indicar su localización, intensidad y si existe sangre intraparenquimatosa o intraventricular.

Pero la TAC tiene máxima sensibilidad en las primeras 12-24 h del sangrado y va perdiendo valor con el transcurso de los días, alcanzando valores del $50 \%$ en la primera semana, del $30 \%$ a las 2 semanas, y casi del $0 \%$ a las 3 semanas (1).

La sensibilidad puede también ser menor si el TAC es informado por personal inexperto o no especialista.

De ahí que siempre con una sospecha clínica de HSA y TAC normal deberemos realizar una punción lumbar con el fin de demostrar sangre en el Líquido Cefalorraquídeo (LCR).

Su sensibilidad es máxima a las $12 \mathrm{~h}$ del sangrado y se mantiene hasta pasadas dos semanas, que empieza a decrecer (1).

El problema crucial es diferenciar entre un LCR hemorrágico por HSA y una punción lumbar traumática con sangrado al realizarla (5).

\section{CASO APORTADO}

Presentamos el caso de una mujer de 45 años sin antecedentes personales de interés, que acude al Servicio de Urgencias por haber presentado hace 18 días de forma brusca dolor intenso a nivel cervical irradiado a zona frontotemporal, que se acentuaba con los movimientos cervicales y con la bipedestación, que aumentaba progresivamente a lo largo del día, con nauseas, mareos y fotofobia.

La paciente no había presentado mejoría del dolor con el tratamiento analgésico y antiinflamatorio, pautado por su médico de cabecera.

En la exploración física la paciente presentaba dolor a la flexión y movilización con contractura voluntaria cervical. No existían signos meníngeos claros ni focalidad neurológica evidente.

Se realizó una Tomografía Axial Computerizada cerebral donde no se apreciaron signos de sangrado.

Con la sospecha de hemorragia subaracnoidea se realizó una punción lumbar, con el resultado de la bioquímica urgente de 303 hematíes en el primer tubo y 301 en el tercero. Se solicitó una centri- fugado del líquido cefalorraquídeo, donde se demostró la presencia de xantocromía en el sobrenadante.

La Resonancia Nuclear Magnética cerebral confirmó posteriormente el diagnóstico.

\section{DISCUSIÓN}

La punción lumbar practicada de urgencia con LCR sanguinoliento para el diagnóstico definitivo de una HSA puede inducir a error en la interpretación de los hallazgos del LCR, y deberemos siempre diferenciarla de una punción traumática.

Cuando en una punción lumbar practicada a un paciente con sospecha clínica de HSA y TAC normal, obtenemos un LCR con un recuento de hematíes superior a lo normal (10 hematíes por campo), se nos plantea la incertidumbre de si estamos ante una punción lumbar traumática.

En una punción lumbar la aguja debe atravesar la capa cutánea, subcutánea, muscular, las fascias, epidural y tejido dural hasta alcanzar el espacio subaracnoideo. Las venas están presentes a lo largo de todo el trayecto, en el periostio, en el saco tecal, y en el espacio epidural anterior. Las estructuras vasculares mayores están en el espacio epidural, y la más larga está anterior al saco tecal, inmediatamente detrás del cuerpo vertebral. Para minimizar el sangrado deberemos acceder al espacio subaracnoideo con un paso único de la aguja, evitando las estructuras óseas y el plexo venoso epidural anterior (5).

En primer lugar debemos demostrar la presencia de sangre en LCR. La visualización directa permite detectar niveles superiores de 700-6.000 células $/ \mathrm{mm}^{2}$, apreciando un tinte de rosa a rojo. En algunos casos podremos apreciar un tinte de rosado-naranja o amarillo debido a los productos de degradación de hematíes antiguos (6).

Es necesario un análisis cuantitativo del número de hematíes en el LCR. Aunque, en teoría, incluso un único hematíe en el LCR puede representar una HSA, en la práctica la mayoría de las punciones lumbares en HSA tienen altos niveles de eritrocitos, superiores a $400-1.000$ células $/ \mathrm{mm}^{2}$, y las punciones lumbares traumáticas tienen niveles mucho menores6.

Pero necesitamos otras técnicas más fiables para poder diferenciar entre estas dos entidades.

Un método tradicional es la prueba de los tres tubos, donde determinaremos el número de hematíes en cada uno de los tres tubos. Si estamos ante una punción lumbar traumática, el número de eritrocitos irá disminuyendo progresivamente en cada tubo, al contrario que en la HSA que se mantendrán. Pero esta técnica no es suficientemente fiable para excluir una HSA (7).

Otras determinaciones de laboratorio propuestas son la presencia de Ferritina o Dímero-D positivo en LCR, que suele ser más común en la HSA (8).

También se ha apuntado que una visualización de hematíes deformados en LCR, sugiere una HSA, ya que éstos se deforman con el tiempo tras su paso a LCR.

Tras el paso de sangre al LCR comienza a las 2-4 horas la deformación y lisis de los hematíes, formándose oxihemoglobina que puede detectarse a las 2-12 horas siguientes al sangrado y da a éste un color rosado o naranja, y la oxihemoglobina se va convirtiendo en bilirrubina a los 3-4 días, adquiriendo un color amarillo. A los 10 días se formará metahemoglobina por oxidación del grupo hemo (1).

La presencia de oxihemoglobina, bilirrubina y metahemoglobina da una coloración amarillo o rosada al sobrenadante del LCR, demostrable tras centrifugación de éste y conocido 
con el nombre de xantocromía. Para evitar falsos positivos deberemos llevar la muestra al laboratorio lo más rápidamente posible.

Podemos encontrar falsos positivos de xantocromía en casos de contaminación sanguínea de la punción lumbar, demora entre la punción lumbar y el centrifugado del LCR, nivel de proteínas superior a $150 \mathrm{mg} / \mathrm{dl}$, bilirrubina plasmática de $10-15 \mathrm{mg} / \mathrm{dl}$, hipercarotinemia, melanomatosis maligna, consumo de rifampicina, o punción lumbar traumática anterior (> 12 horas) (9).

Por lo tanto cuando la xantocromía está presente la hemorragia ha ocurrido antes de que la punción lumbar se realizara. Son necesarias unas 12 horas del sangrado para que la xantocromía alcance el $100 \%$ de sensibilidad.

\section{Bibliografía}

1. Van Gijn J, Rinkel GJE. Subarachnoid haemorrhage: diagnosis, causes and management. Brain 2001; 124: 249-78.

2. Longstreth WT Jr, Nelson LM, Koepsell TD, van Belle G. Cigarette smoking, alcohol use, and subarachnoid hemorrhage. Stroke 1992; 23: 1242-9.

3. Bonita R, Thomson S. Subarachnoid haemorrhage: epidemiology, diagnosis, management, and outcome. Stroke1985; 16: 591-4.

4. Bassi P, Bandera R, Loiero M, Tognoni G, Mangoni A. Warning signs in subarachnoid hemorrhage: A cooperative study. Acta Neurol Scand 1991; 84: 277-81.

5. Foot C, Staib A. How valuable is a lumbar puncture in the management of patients with suspected subarachnoid haemorrhage? Emerg Med 2001; $13: 326-32$.
Sin embargo existe controversia acerca del método por el que debería demostrarse la xantocromía.

La inspección visual directa no es suficientemente sensible para detectarla en muchos casos de HSA.

Se recomienda la espectrofotometría como método más sensible para demostrar la xantocromía en LCR en los casos de HSA (9).

La Resonancia Nuclear Magnética (RNM) aunque no es de utilidad en los pacientes de Urgencias con sospecha de HSA, podría tener mayor sensibilidad que la TAC convencional (10).

Una vez realizado el diagnóstico clínico y de imagen de una HSA queda conocer el origen de la misma. Para ello se realiza una angiografía diagnóstica de todos los troncos cerebrales.

6. Seehusen DA, Reeves MM, Fomin DA. Cerebrospinal fluid analysis. Am Fam Physician 2003; 68: 1103-8.

7. Shah KH, Edlow JA. Distinguishing traumatic lumbar puncture from true subarachnoid hemorrhage. J Emerg Med 2002; 23: 67-74.

8. Page KB, Howell SJ, Smith CM, Dabbs DJ, Malia RG, Porter NR, et al. Bilirubin, ferritin, D-dimers and erythrophages in the cerebrospinal fluid of patients with suspected subarachnoid haemorrhage but negative computed tomography scans. J Clin Pathol 1994; 47: 986-9.

9. Edlow JA, Bruner KS, Horowitz GL. Xanthochromia. Arch Pathol Lab Med 2002; 126: 413-5.

10. Ogawa T, Inugami A, Shimosegawa E, Fujita H, Ito H, Toyoshima H, et al. Subarachnoid hemorrhage: evaluation with MR imaging. Radiology 1993; 186: 345-51. 